\title{
GIDALARDA AKILLI AMBALAJLAMA TEKNOLOJİSİ VE GÜNCEL UYGULAMALAR
}

\author{
Dilara Konuk Takma, Hilal Şahin Nadeem* \\ Adnan Menderes Üniversitesi, Mühendislik Fakültesi, Gıda Mühendisliği Bölümü, 09010, Aydın, Türkiye \\ Geliş / Received: 27.09.2018; Kabul / Accepted: 14.01.2019; Online bask1 / Published online: 20.02.2019
}

Konuk Takma, D., Şahin Nadeem, H. (2019). Gıdalarda ak1llı ambalajlama teknolojisi ve güncel uygulamalar. GID $A$ (2019) 44 (1): 131-144 doi: 10.15237/gida.GD18106

Konuk Takma, D., Sahin Nadeem, H. (2019). Grdalarda akill ambalajlama teknolojisi ve güncel uygulamalar. GIDA (2019) 44 (1): 131-144 doi: 10.15237/gida.GD18106

\section{ÖZ}

Akıllı ambalajlama, gida ambalajlama teknolojisinde öne çıan en yeni paketleme sistemidir. Üreticiler, perakendeciler ve tüketiciler tarafindan gıda güvenliği ve kalitesinin izlenebilirliği için yenilikçi ambalajlara artan talep, akıllı ambalajlama teknolojisinin ortaya çıkmasina neden olmuştur. "Akıllı" terimi, ambalajin içinde veya dışında meydana gelen değişikliklere yanıt verebilmesini ve ürünün durumunu tüketicilere aktarabilmesini ifade etmektedir. Akıllı ambalajlama, birincil ambalaj fonksiyonlarının yanı sıra, gida atıklarının önlenmesi veya azaltılması, gıda güvenliğinin sağlanması, ürün kalitesinin ve besleyici değerinin izlenebilmesini sağlamaktadır. Son yıllarda yapılan çalışmalar, sıcaklığa ve bozulmaya bağlı olarak renk değiştiren barkodlar ve etiketler, modifiye atmosferde paketlenmiş ürünlerde sızıntı kontrolünü sağlayan kolorimetrik indikatörler, taze ürünlerin olgunluk derecesine bağlı olarak renk değisstiren filmler ve biyosensörler gibi akıllı ambalajlama araçlarının geliştirilmesi üzerine yoğunlaşmıştır. Bu derlemede, gıdalarda kullanılan akıllı ambalajlama sistemleri, bu sistemlerin çalsşma prensipleri, geliştirilen akıllı ambalajlar ve gıda uygulamaları hakkında güncel bilgilere yer verilmiştir.

Anahtar kelimeler: gıda ambalajlama, akıllı ambalaj, akıllı etiket, ambalaj indikatörleri, sensörler

\section{INTELLIGENT PACKAGING TECHNOLOGY IN FOODS AND CURRENT APPLICATIONS}

\begin{abstract}
Intelligent packaging is the newest packaging system in food packaging technology. Increasing demand for innovative packagings by producers, retailers, and consumers to monitor quality and safety of food has led to arise intelligent packaging. The term "intelligent" refers to the response to changes occurring inside or outside packaging and transferring status of the product to consumers. Intelligent packaging, besides the primary functions of packaging, provides preventing or reducing food waste, ensuring food safety, monitoring quality and nutritional value of product. Recent studies have focused on the development of intelligent packaging devices such as color-changing barcodes and labels based on temperature and deterioration, colorimetric indicators providing leakage control of products packaged in a modified atmosphere, color-changing films depending on the degree of maturity of fresh products, and biosensors. In this review, intelligent packaging systems, the working principles of these systems, and recent information about intelligent packaging and food applications are presented.
\end{abstract}

Keywords: food packaging, intelligent packaging, intelligent label, packing indicators, sensors

\footnotetext{
* Yazışmalardan sorumlu yazar / Corresponding author;

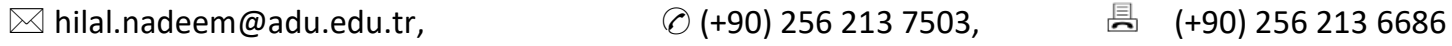




\section{GİRİ̧̧}

Gıda endüstrisinde ambalaj, gıdaların kalitesinin korunmasi, kontaminasyonların önlenmesi, taşınması ve depolanması için kullanılan bir çeşit koruma sistemidir (Otles ve Sahyar, 2016). Genel hatlarıla ambalajin fonksiyonları muhafaza, koruma, iletişim ve kolaylık olmak üzere 4 başlık altında toplanabilir. Ambalaj; gıdanın üretim hattını terk etmesinden itibaren gidayı içinde bulundurarak tüketiciye ulaşıncaya kadar muhafaza işlemini gerçekleştirmektedir. Ambalaj ürünü fiziksel ve mekanik etkilere karşı koruduğu gibi, aroma kaybını önleme, 1şık geçirmezliği sağlama ve mikrobiyolojik koruma da sağlamaktadır. Muhafaza ve koruma fonksiyonları dışında ambalaj tüketici ile ürün arasındaki iletişimi de sağlamaktadır. Ambalajın kolaylık fonksiyonu ise ürünü kolay açma, kapama, boşaltma, taşıma, depolama, rafa yerleştirme gibi kolaylıkları kapsamaktadır (Singh ve Heldman, 2014).

Tüketici talepleri, teknolojinin ilerlemesi ve gida endüstrisinin eğilimleri doğrultusunda gıda ambalajlama teknolojileri sürekli olarak gelişme göstermektedir. Son yillarda ambalaj materyaline fonksiyonel özelliklerin kazandırıldığı yeni ambalajlama teknolojileri ortaya çıkmıştır. Bunlar aktif ve akıllı ambalajlama teknolojileri olarak iki grupta sinıflandırılmaktadır (Realini ve Marcos, 2014). Aktif ambalajlama teknolojisinde, gidadaki bozulma reaksiyonlarının hizının azaltılması ve gıdanın raf ömrünün daha da uzatılabilmesi için oksijen tutucular, nem emiciler, antimikrobiyal ajan salıcıları, etilen tutucular ve koku emiciler gibi çeşitli aktif bileşenlerin ambalaj malzemesine veya ambalaj içine eklenmesinden yararlanılır (Shin ve Selke, 2014; Fang vd., 2017). Akıllı ambalajlama teknolojisi ise gıdanın güvenliği ve kalitesi hakkında üretici ve tüketiciye bilgi verebilen ve ürün kalite ve güvenliği hakkında erken uyarılarda bulunan ambalaj sistemleridir (Üçüncü, 2011). Gıda ürünlerinin ve ürünlerin lojistiğinin giderek daha kapsamlı ve karmaşı bir hale gelmesi sonucu belirtilen raf ömrünü, ürün kalitesini, besleyici değerini ve gıda güvenliğini sağlamak için yeni gereksinimlere ihtiyaç duyulmaktadır. Özellikle gida güvenliğiyle ilgili olarak, küresel gida güvenliği otoritelerinin son y1llarda çalıştıkları, gıdalarda izlenebilirlik sistemlerinin uygulaması üzerine konuların desteklendiği açık bir şekilde görülmektedir (Kerry, 2014). Bu derlemede son yıllarda hızla gelişme gösteren akıllı ambalajlama teknolojisi ve gidalarda güncel uygulamalarına ilişkin bilgiler özetlenmiştir.

\section{AKILLI AMBALAJLAMA KAVRAMI}

Akıllı gida ambalaj1, gidanin ve etrafindaki çevrenin şartlarını izleyebilen madde ve materyaller olarak ifade edilmektedir. Bu ambalajlar; taşıma ve depolama boyunca gıdayı veya gidanın çevresini izleyerek meydana gelen bazı değişimler sonucu ürünün tazeliği ve güvenliği hakkında üretici, satıcı ve tüketiciye bilgi sağlamaktadır (Majid vd., 2016; de Kruijf vd., 2002). Akıllı ambalajlama sistemleri iki grupta siniflandirilmaktadır. Bunlar; ak1llı etiketler ve ambalaj indikatörleridir. Akıllı etiketler; barkodları ve radyo frekanslı tanımlama etiketlerini (RFID) kapsamaktadır. Ambalaj indikatörleri; sıcaklıksüre indikatörleri, sızıntı $\left(\mathrm{O}_{2}\right.$ ve $\mathrm{CO}_{2}$ indikatörleri), tazelik indikatörleri ve biyosensörleri içermektedir (Taoukis ve Tsironi, 2016). Ak1ll ambalajlama sistemleri, ambalajlanan ürün hakkındaki verilerin, ambalaja akılllik özelliği kazandıran bu etiketler ve indikatörler aracıllğıyla işlenmesi ve elde edilen bilgilerin tüketiciye aktarılması şeklinde çalışır. Tüketiciye ürünün kalitesi, tazeliği, raf ömrü, kullanım koşulları hakkında bilgi verir. Akıllı ambalajlama sistemlerinin çalışma prensipleri; sıcaklık-süre ölçümü, kimyasal veya mikrobiyolojik kalite değişimlerinin ölçümüne dayanır (Yam vd., 2005). Akıllı paketleme sisteminde kullanılan göstergeler, ambalaj üzerine yapıştırılabilir veya paket içerisine entegre edilebilir. Gida ambalaj malzemesine dahil edilen veya üzerine etiketlenen akıllı ambalajlama sistemleri, tedarik zinciri boyunca ürün kalitesini izlemek, kritik noktaları kontrol etmek ve daha ayrıntılı bilgi vermek için olanaklar sunmaktadır (Dobrucka, 2013). Ak1llı ambalajların geliştirilmesinde, gida kalitesinin veya raf ömrünün tahmininde sensör sinyalini sağlamak için matematiksel modelleme oldukça önemlidir. Sensör verileri ve gıda kalitesi arasındaki ilişkiyi modellemek için gida kalitesini etkileyen reaksiyonların kinetiğinin bilgisi gereklidir (Heising vd., 2014). 


\section{Akıllı Etiketler}

Ambalaj üzerinde yer alan ve ürünün özelliklerini tanımlamak amacıyla kullanılan bir işaretleme yöntemi olan barkodlara akıllı özellik kazandırılarak, gıdadaki bozulmalara paralel olarak değişimleri sağlanmaktadır. Termokromik pigmentler içeren mürekkep kullanılarak geliştirilen barkodlar, belli sıcaklıklarda renk değişimi göstererek gidalarda sicaklık değişimlerini gözlemleyebilmektedir. Özellikle soğukta muhafaza edilen gida ürünlerinde kullanılmak üzere geliştirilen bu akıllı barkodlar, sıcaklık değişimi gerçekleştiğinde mor renge dönmekte ve barkod tarandığında veri aktarımı yapamaz hale gelmektedir. $\mathrm{Bu}$ sayede riskli gidalarda bozulma durumunda ürünün barkodunun okunmaması sonucu satışının gerçekleşmemesi ve otomatik olarak elenmesi sağlanır (Lee ve Rahman, 2014). Şekil 1.a' da TRACEO firması tarafindan tazelik indikatörü olarak geliştirilen ticari barkodlar görülmektedir. Radyo frekanslı tanıma sistemi (Radio frequency information device (RFID)), radyo dalgaların kullanarak etiket okumayı sağlayan bir teknolojidir. $\mathrm{Bu}$ sistemin çalışma prensibi, mikroçiplerin ürüne yerleştirilerek, fiziksel etkileşim yerine, ürünlerin kimliklerini radyo dalgalarıyla okuyabilmesine dayanır (Lee ve Rahman, 2014). RFID etiketler, gida ile hareket ederek ürün ve ürünün geçmişi hakkındaki tüm bilgileri taşır. RFID etiketleri gidanın sıcaklık, bağıl nem ve tüketim talimatları gibi bilgilerini taşımakla birlikte, radyo dalgaları aracıllğıyla ürünü uzaktan takip edebilmektedir (Karagöz ve Demirdöven, 2017). Bu sistem ile ürün verilerinin uzaktan erişerek okunabilmesi depolama ve stok takibinde kolaylık sağlamaktadır. Disk, cam kapsül, etiket gibi farklı biçimlerde bulunabilen bu etiketlerin diğer indikatörlerle de birleştirilebildiği belirtilmiştir (Yuksel ve Zaim, 2009). RFID uygulamaları, son on yılda üretim ve dağıtım zincirinin tüm aşamalarında iyi izlenebilirlik ile ilgili olarak aşamalı olarak geliştirilmiştir. Gıda ürünlerinin menşei, kalitesi, lojistik aşamaları, muhafaza sıcaklikları hakkında üreticiden tüketiciye bilgi aktarımını sağlayabilmektedirler (Costa vd., 2013).

\section{Ambalaj indikatörleri}

Ambalaj indikatörleri, bir maddenin varlığına veya yokluğuna, iki veya daha fazla madde arasındaki bir reaksiyonun derecesine veya belirli bir madde veya madde sınıfinın konsantrasyonuna bağlı olarak renk yoğunlukları veya gösterge boyunca bir boyanın difüzyonu gibi görsel efektler ile tüketiciye bilgi vermektedir. $\mathrm{Bu}$ bilgiler doğrultusunda gidanın kalitesi, tazeliği, veya oluşabilecek mikrobiyal bozulmaların varlığ1 anlaşılmaktadır (Ghaani vd., 2016). Ambalaj indikatörleri, özellikle kısa sürede tüketilen et, tavuk ve balık gibi gıda ürünlerinde mikrobiyal kontaminasyon veya uygunsuz koşullarda muhafaza sonucu mikrobiyal gelişmelerin oluşumunun göstergesi olarak önemli rol oynar ve gıda kaynaklı hastalıkları azaltır (Kerry, 2014).

Gidaların bozulmasındaki temel nedenlerden biri sıcaklıktır. Gıdaların taşıma ve depolama sırasındaki sıcaklık kontrolü, mikroorganizmaların gelişmesi, metabolik aktiviteler ve diğer kimyasal, duyusal ve besinsel reaksiyonlar üzerine olan etkisinden dolayı önemlidir (Karel ve Lund, 2003). Zaman-sıcaklık indikatörleri; gidanın sicaklık geçmişinin, kimyasal, elektrokimyasal ve enzimatik reaksiyonlar sonucu geri dönüşümsüz olarak bildirilmesini sağlayan araçlardır (Shimoni vd., 2001). Özellikle dondurulmuş gidalar, et ve et ürünleri, dondurulmuş meyve ve sebzeler, süt ve süt ürünlerinde sicaklığın artmasindan kaynaklanan mikrobiyal, enzimatik ve biyokimyasal bozulmalara karşı son derece duyarlı indikatörlerdir. Zaman sicaklık indikatörleri sayesinde soğuk zincir ürünlerin denetimi etkili bir şekilde yapilabilmektedir (Taoukis ve Tsironi, 2016). Şekil 1.b' de Fresh-Check ${ }^{\circledR}$ firmas1 tarafindan geliştirilen tazelik indikatörü görülmektedir.

Tazelik indikatörlerinin çalışma prensibi, mikrobiyal bozulma sonucu oluşan organik asitler, etanol, uçucu azot bileşikleri, karbondioksit ve kükürtlü bileşikler gibi metabolitlerin varlığında ambalaj üzerindeki etiketin renk değiştirmesine dayanmaktadır. Amonyak, dimetilamin ve trimetilamin gibi uçucu azot bileşenleri balıklarda bozulmanın bir göstergesi olarak kabul edilmektedir. $\mathrm{Bu}$ tip 
etiketler özellikle modifiye atmosfer paketleme (MAP) tekniği ile paketlenen et ürünlerinde kullanılmaktadır (Smolander, 2008). Tazelik indikatörleri, $\mathrm{pH}$ değişimine, uçucu azot bileşiklerine, hidrojen sülfüre $\left(\mathrm{H}_{2} \mathrm{~S}\right)$, veya mikrobiyal metabolitlere duyarlı olmak üzere çalışma prensiplerine göre 4 gruba ayrılmaktadır. Ambalajin tepe boşluğunda toplanan uçucu azot bileşiklerinin veya sülfitlerin etkisiyle $\mathrm{pH}$ değişmekte ve bu durum $\mathrm{pH}$ indikatörlerinde renk değişiminin olmasıyla anlaşılmaktadır (Öksüztepe ve Beyazgül, 2015). Hidrojen sülfüre $\left(\mathrm{H}_{2} \mathrm{~S}\right)$ duyarlı tazelik indikatörleri genellikle et ve et ürünlerinin kalitesini belirlemek için kullanılmaktadır (Ghaani vd., 2016).

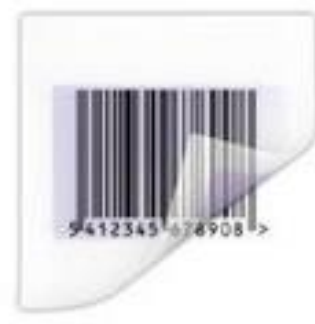

Ürün tazeliğini gösteren şeffaf, okunabilir barkod

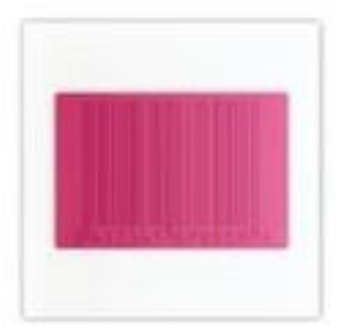

Tüketime uygun olmayan ürünü gösteren mat, okunamayan barkod

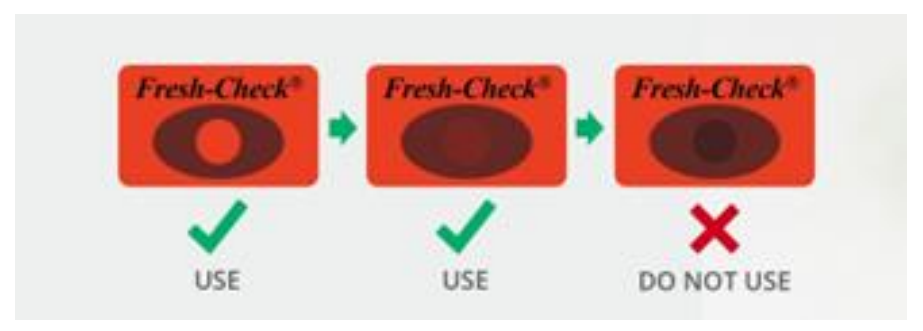

Şekil 1. TRACEO firması tarafından tazelik indikatörü olarak geliştirilen barkodlar (a) (Kokangül ve Fenercioğlu, 2012) , Fresh-Check ${ }^{\circledR}$ (2018) firması tarafından geliştirilen tazelik indikatörü (b)

Oksijen birçok gıdanın bozulmasından sorumlu ana faktörlerden biridir. Gidalarda oksijen varlı̆̆ında gerçekleşen oksidatif reaksiyonlar, ürünlerin besin değeri, aroma ve renk gibi kalite özelliklerini olumsuz yönde etkilerken, aerobik mikroorganizmaların büyümesine ortam sağlayarak bozulmaya katkıda bulunur (Dalmoro vd., 2017). Özellikle MAP ambalajlı gidalarda uzaklaştırılan havanın yerine formüle edilmiş bir gaz karışımı ile paketlenmesi ve ürünün herhangi bir sızıntı olmadan tüketiciye ulaşması önemlidir. Sizınt1 indikatörleri modifiye atmosferde ambalajlanan gidalarda gazların varlığını ya da yokluğunu gösteren, ambalaj bütünlüğü ve sızıntıları hakkında bilgi verebilen indikatörlerdir (Heising vd., 2014). Bu indikatörler kimyasal ve enzimatik reaksiyonların bir sonucu olarak renk değiştirirler. İndikatörler; tablet, etiket, baskı şeklinde olabildiği gibi, polimer film kaplanarak da formüle edilebilmektedir (Üçüncü, 2011). Bu indikatörlerin dezavantaj1 yüksek hassasiyete sahip olmasıdır. Çok düşük $(\sim 0.1 \%)$ oksijen konsantrasyonunda indikatörde değişim olabileceği ifade edilmiştir. Bu durum dikkate alınarak geliştirilen oksijen indikatörleri, ticari olarak bir dizi şirket tarafindan üretilmektedir (Kerry vd., 2006).

\section{Sensörler}

Sensörler, fiziksel veya kimyasal bir özelliğin tespiti veya ölçümü sonucu bir sinyal vererek, bir maddenin varllğının tespit edilmesi için kullanılmaktadır (Ghaani vd., 2016). Sensörler zaman alıc1 ve maliyetli analizlere bir alternatif sunmasına rağmen, ticari olarak kullanımlarındaki bazı engellerin aşılması gerekmektedir. Bunlar; 
boyutunun küçültülmesi, esnekliğin arttırllması, üretim maliyetinin azaltılmas1, sağlamlığın arttırilmas1, mevzuata uygun olmasi ve gida güvenliğini göz önünde bulundurmasıdır (Vanderroost vd., 2014). Ak1llı ambalaj geliştirmek için özellikle gıda bozulması veya paket sızıntıları ile ilgili uçucu organik bileşikleri ve gaz moleküllerini $\left(\mathrm{H}_{2}, \mathrm{CO}_{2}, \mathrm{O}_{2}, \mathrm{H}_{2} \mathrm{~S}, \mathrm{NH}_{3}\right.$, vd. izleyebilen küçük ve esnek sensörler son zamanlarda oldukça ilgi çekmektedir (Tang vd., 2010). Akıllı ambalajda kullanılan bazı sensör tipleri, kimyasal sensörler, biyosensörler ve gaz sensörleridir. Kimyasal sensörler, gıda kalitesinin ve ambalaj bütünlügünün izlenmesinde daha yaygın görülmektedir. Bu sensörler, sıv1 veya gaz fazında olan ortamın kimyasal bileşimi hakkında bilgi sağlayabilmektedir. Gaz sensörleri, gaz formundaki bakteri metabolitlerinin konsantrasyonlarında oluşan bir değişikliğe bağlı olarak, karbondioksit üretimi gibi, gida ürününde bakteri üremesi gerçekleştiğini göstermektedir (Dalmoro vd., 2017). Özellikle et ürünlerinde mikrobiyal büyüme ile ilgili kimyasal değişikliklerin tespiti amaciyla aminlerin belirlenmesi için amperometrik biyosensörler, hidrojen peroksiti tespit etmek için platin elektrotları, ve enzimlere dayalı sistemler gibi bir takım enstrümental teknikler ile sensörlerin geliştirilmesi hedeflenmiştir (Huang vd., 2011). Sensörler, geleceğin akıllı paketleme sistemleri için en umut verici ve yenilikçi teknoloji olarak kabul edilmektedir.

\section{GÜNCEL UYGULAMALAR}

Ak1llı gida ambalajlama uygulamaları ve yeni akı1lı indikatör araçlarının geliştirilmesi yönünde yapılan çalışmalar giderek artmaktadır. Özellikle, kullanımının kolay ve düşük maliyetli olması nedeniyle, gidaların akıllı ambalajında kolorimetrik $\mathrm{pH}$ indikatörleri yaygın bir şekilde uygulanmaktadır. Genellikle tazelik indikatörü olarak kullanılan bu indikatörler, gıdalarda mikrobiyal bozulma veya metabolizmanın bir sonucu olarak üretilen metabolitlerin varlığında renk değişimi prensibine dayanmaktadır. Metabolitler gıdanın çeşidine göre farklılık göstermekle birlikte, organik asitler, etanol, karbondioksit, azot bileşikleri veya uçucu diğer bileşikleri içermektedir. İndikatör madde duyarlı olduğu metabolit konsantrasyonunda artış sonucu renk değiştirmektedir. Saliu ve Della Pergola (2018) tarafindan geliştirilen lisin/polilisin/antosiyaninler içeren kolorimetrik indikatör karbondioksit varlığında mavi renkten pembe renge dönüsserek gida tazeliğindeki azalmayı göstermektedir. Tavuk eti ambalajlarına yerleştirilen bu indikatör, mikrobiyal gelişme ile uyumlu olarak renk değişimi göstermiştir. Ma vd. (2018) tarafindan dut ekstrakt1, polivinilalkol ve kitosan nanopartiküllerine enkapsüle edilerek geliştirilen akıllı filmler balık bozulmalarının izlenmesinde test edilmiştir. Depolama süresince balıklardaki bozulmaya paralel olarak indikatörün rengi kırmızıdan yeşile dönmüştür. Ambalaj içerisinde biriken azotlu bileşikler ortam $\mathrm{pH}$ 'sını arttırarak indikatörde renk değişimine neden olmuştur. Zhang vd. (2018) tarafindan domuz etlerinde tazeliği izlemek amaciyla roselle antosiyaninleri içeren ve biyobozunur polimer olarak nişasta, polivinil alkol ve kitosanın ikili kombinasyonlarının kullanıldığı akıllı filmler geliştirilmiştir. Filmlerin özellikleri incelendiğinde, nişasta/polivinil alkol/roselle antosiyaninleri ile oluşturulan film en yüksek antioksidan aktiviteye sahip iken, polivinil alkol/ kitosan/roselle antosiyaninleri ile oluşturulan film en yüksek çekme mukavemetine sahip olduğu bulunmuştur. Yüksek antioksidan aktivitesi antosiyaninlerin film yapısına immobilize edildiğinin göstergesi olup, bu filmler aynı zamanda en iyi renk stabilitesi göstermiştir. Geliştirilen filmlerde elde edilen yüksek çekme mukavemeti ile kitosan bazlı filmlerin zayıf mekanik özellikleri aşılmıştır. Nişasta/polivinil alkol/roselle antosiyaninleri ile oluşturulan film, $25^{\circ} \mathrm{C}$ 'de muhafaza edilen domuz etinin tazeliğini izlemek için kullanıldığında filmin kırmızıdan yeşile doğru renk değişimi gösterdiği görülmüştür. Başka bir çalışmada ise domuz etinin depolanması süresince oluşan aminlerin hassas tespiti için 1spanak, kırmızı turp, kış yasemini ve siyah pirinçten elde edilen dört farklı doğal renk pigmentine dayalı kolorimetrik sensörler geliştirilmiştir. Bozulma boyunca ortamda oluşan amin bileşiklerine karşı siyah pirinç ekstraktının en hassas olduğunu belirlenmiştir. Farklı pigmentlerin uçucu maddelere karşı farklı hassasiyet göstermesi bileşimlerinde bulunan renk pigmentlerine bağlı olup, ıspanakta klorofil, kış 
yasemininde karotenoidler, kırmızı turp ve siyah pirinçte ise antosiyaninler rol oynamaktadır. Yapılarında yer alan karbonil ve hidroksil gruplarının amin bileşiklerini bağlaması nedeniyle antosiyaninlerin daha etkili olduğu belirtilmektedir (Xiao-wei vd., 2014).

Çizelge 1. İndikatör özelliği gösteren akıllı filmlerin bileşimi, kullanım amaçları ve gıda uygulamaları üzerine yapılan güncel çalışmalar

\begin{tabular}{|c|c|c|c|}
\hline $\begin{array}{l}\text { İndikatör Özelliği Gösteren } \\
\text { Akı1lı Filmlerin Bileşimi }\end{array}$ & Kullanım Amac1 & G1da Uygulamas1 & Referans \\
\hline Lisin/Poli-lisin/Antosiyaninler & $\begin{array}{c}\text { Mikrobiyolojik } \\
\text { yönden kalitenin } \\
\text { değerlendirilmesi }\end{array}$ & Tavuk eti & $\begin{array}{l}\text { Saliu ve Della Pergola } \\
\text { (2018) }\end{array}$ \\
\hline $\begin{array}{l}\text { Polivinil alkol/Kitosan/Dut } \\
\text { ekstrakt1 }\end{array}$ & $\begin{array}{l}\text { Ürün tazeliğinin } \\
\text { değerlendirilmesi }\end{array}$ & Balık & Ma vd. (2018) \\
\hline $\begin{array}{l}\text { Nişasta/Polivinil alkol/Roselle } \\
\text { antosiyaninleri }\end{array}$ & $\begin{array}{l}\text { Ürün tazeliğinin } \\
\text { değerlendirilmesi }\end{array}$ & Domuz eti & Zhang vd. (2018) \\
\hline Nişasta/Polivinil alkol/Limonen & $\begin{array}{c}\text { Mikrobiyolojik } \\
\text { yönden kalitenin } \\
\text { değerlendirilmesi }\end{array}$ & Pastörize süt & Liu vd. (2017) \\
\hline $\begin{array}{l}\text { Nişasta/Polivinil alkol/ } \\
\text { Antosiyaninler }\end{array}$ & $\begin{array}{l}\text { Ürün tazeliğinin } \\
\text { değerlendirilmesi }\end{array}$ & Balık & Zhai vd. (2017) \\
\hline $\begin{array}{l}\text { Tara gum/Polivinil } \\
\text { alkol/Zerdeçal }\end{array}$ & $\begin{array}{l}\text { Ürün tazeliğinin } \\
\text { değerlendirilmesi }\end{array}$ & Karides & Ma vd. (2017) \\
\hline Patates Nişastas1/ Antosiyaninler & $\begin{array}{c}\text { Mikrobiyolojik } \\
\text { yönden kalitenin } \\
\text { değerlendirilmesi }\end{array}$ & Domuz eti & Choi vd. (2017) \\
\hline Kitosan/ Çiçek Ekstraktları & $\begin{array}{l}\text { Ürün tazeliğinin } \\
\text { değerlendirilmesi }\end{array}$ & Domuz eti, Balık & Zhang vd. (2014) \\
\hline
\end{tabular}

İndikatör özelliği gösteren akıllı filmlerin bileșimi, kullanım amaçları ve gıda uygulamaları üzerine yapilan güncel çalş̧malar Çizelge 1'de özetlenmiştir. Liu vd. (2017) tarafindan geliştirilen limonen ile zenginleştirilmiş filmler pastörize sütlerde 48 saat sonunda pembe renkten kırmızı renge geçişi görülmüştür. Zhai vd. (2017) tarafindan geliştirilen antosiyaninler içeren kolorimetrik filmler kullanılarak balıklarda bozulma ile oluşan aminlerin birikimi sonucu antosiyaninlerin pembe-mor rengi mavi renge dönüşerek ürün tazeliği hakkında bilgi vermektedir. Tatlı mor patatesten ekstrakte edilen antosiyanin ekstraktının ilave edildiği patates nişastasindan elde edilen filmler domuz etlerinde bozulmayla beraber pembeden yeşile doğru renk değișimi göstermiștir (Choi vd., 2017). Bir diğer çalışmada, amonyak indikatörü olarak kullanılmak üzere tara gum/polivinil alkol bazlı ve zerdeçal içeren kolorimetrik filmler geliştirilmiştir (Ma vd., 2017). Geliştirilen filmler karideslerde tazelik göstergesi olarak kullanıldı̆̆ında, mikrobiyal bozulma sonucu oluşan amonyak varlığında gözle görülür bir biçimde sarıdan kahverengiye doğru renk değişimi göstermiştir. Musso vd. (2016) jelatin bazlı filmlere zerdeçal ilave ederek, $\mathrm{pH}$ 'ya bağl1 renk değişimi gösteren akıllı film materyalleri geliştirmişlerdir. $\mathrm{pH}=6$ 'da sarı renk gösteren filmler, $\mathrm{pH}=11$ 'de kırmızı renk göstermiştir. Baubinia blakeana Dunn çiçeğinden ekstrakte edilen doğal boyalar kullanilarak kitosan bazlı kolorimetrik $\mathrm{pH}$ değişimine duyarlı filmler 
geliştirilmiştir. Film rengi, $25^{\circ} \mathrm{C}^{\prime}$ de muhafaza edilen domuz eti ve balık örneklerinde yaklaşık 12 saat sonra mordan kahverengiye, 24 saat sonra kahverengiden yeşile doğru değişmiştir (Zhang vd., 2014).

Literatürde gıda uygulamalarının gerçekleştirilmediği fakat indikatör özelliği gösteren potansiyel akıllı filmlerin geliştirildiği çalışmalar da yer almaktadır. Luchese vd. (2017) tarafindan yaban mersini meyve suyu üretiminden açığa çıkan atıklar kullanılarak, mısır nişastası bazlı $\mathrm{pH}$ duyarlı indikatör filmler geliştirilmiştir. Antosiyaninler ve mısır nişastasının oluşturduğu kompleksin pH'ya bağlı renk dönüşümü açığa çıkarılmıştır. Mor tatlı patates antosiyaninleri kullanilarak gellan gum bazlı $\mathrm{pH}$ indikatörleri geliştirilmiş ve proteince zengin gidalarda kullanılabileceği önerilmiştir (Wei vd., 2017). Benzer şekilde kırmızı lahana antosiyaninleri kullanılarak kitosan ve polivinilalkol bazlı $\mathrm{pH}$ indikatörü filmler geliştirilmiş ve taze gidalarda kullanılabileceği önerilmiştir (Pereira vd., 2015). Bir bașka çalışmada ise indikatör boyalar kullanılarak kitosan, sitrik asit, karboksi-metilselüloz bazlı sülfür ve etil alkole duyarlı uçucu bileşik indikatörü geliştirilmiştir. $\mathrm{Bu}$ indikatörlerin özellikle taze meyvelerin olgunlaşma derecesinin göstergesi olarak kullanılabileceği önerilmiştir (Niponsak vd., 2016). Ak1llı ambalajlama uygulaması için kırmızı lahana ve gül ağac1 ekstrelerinden elde edilen doğal renk pigmentleri kullanılarak kolorimetrik bir sensör tasarlanmıştır. Kırmızı lahana ve gül üzerinde bulunan antosiyaninler, $\mathrm{pH}$ arttığında kırmızıdan yeşile doğru değişerek $\mathrm{pH}$ sensörleri olarak davranmıştır (Shukla vd., 2016). Yoshida vd. (2014) doğal antosiyaninlerle $(1 \% \quad \mathrm{w} / \mathrm{w})$ zenginleştirilmiş kolorimetrik $\mathrm{pH}$ indikatörü olarak kullanılmak üzere kitosan $(2 \% \quad \mathrm{w} / \mathrm{w})$ bazlı ak1llı filmler geliştirilmiştir. Farklı pH'lardaki tampon çözeltilerde incelenen filmler asidik koşullarda $(\mathrm{pH}=2.0)$ pembe, nötral koşullarda $(\mathrm{pH}=7.0$ 8.0) mavimsi-yeşil ve bazik koşullarda $(\mathrm{pH}=13.0)$ sar1 renk göstermiştir.

Akıllı filmlerin dışında indikatör özelliği gösteren boyaların farklı materyallere immobilizasyonu ile kullanıldığ1 sensörler de geliştirilmektedir.
Kuswandi ve Nurfawaidi (2017) et tazeliğinin değerlendirilmesi amacıyla metil kırmızısı ve bromkrezol pembesi boyalarının immobilizasyonu ile çiftli sensör geliştirilmiştir. Etin bozulmasiyla beraber bromkrezol pembesi mora dönüşürken, metil kırmızısı sarıya dönüşmüştür. Geliştirilen çiftli sensörlerin yanıtı; toplam canlı sayıs1 ve oluşan uçucu amin bileşikleri ile de uyumlu bulunmuştur. Morsy vd. (2016) tarafindan balıklardaki bozulmayı izleyebilecek çoklu bir indikatör araştırması yapılmıştır. Seçilen 16 renk maddesi silika jele eşit miktarda uygulanarak, örneklerin depolanacağ 1 cam ambalajların kapak kısmına yerleştirilmiştir ve $4^{\circ} \mathrm{C}$ 'de 9gün depolanan balık örneklerinde bozulma sonucu oluşan uçucu bileşiklerin sensörlerde meydana getirdiği renk değişimleri incelenmiştir. Aynı zamanda örneklerde pH, tiyobarbitürik asit, toplam uçucu bazik azot tayini ve toplam canlı sayıs1 analizleri ile indikatör uyumu doğrulanmışır. Chen vd. (2017) tarafindan akıllı barkod geliştirmeye odaklanan bir çalışmada ise düşük maliyetli, kağıt bazlı ve akıllı telefonlara uyumlu bir barkod modeli hedeflenmiştir. Çapraz-reaktif buhar duyarlı boyaların reçine mikroboncuklar içerisine enkapsüle edilerek ve düşük maliyetli bir kağıt alttabakası üzerine emdirilerek elde edilen bir barkod modeline dayanan sensör geliştirilmiştir. Tavuk etinden ç1kan gazların algilanmasında "nil kırmızısı", "çinko tetrafenilporfirin (Zn-TPP)" ve "metil kırmızısı" boyaları kullanılmıstır. Böylece sensörün bir fotoğrafi çekilerek et ürününün durumu akıllı telefonda izlenebilmiştir. Bu şekilde renk bilgisi fotoğraftan çıkarılarak, et kalitesine karar vermek için standart grafik ile karşılaştırılabilmesi sağlanmıştır. Orta nemli hazır tatlılarda akı1lı ambalajlama uygulaması ile mikrobiyal bozulmanın izlenebilirliği için, bromtimol mavisi ve metil kırmızısı boyaları kullanılarak kolorimetrik indikatörler geliştirilmiştir. İndikatör, mikrobiyal metabolitlerden $\mathrm{CO}_{2}$ oluşumuna bağlı olarak kademeli renk değişimi göstermiştir. Birinci aşamada yeşilden sarıya, ikinci aşamada sarıdan turuncuya renk değişimi göstererek, rafömrü sona eren ürünlerde turuncu-kırmızı renk belirlenmiştir (Nopwinyuwong vd., 2010). 
Salinas vd. (2014) tarafindan 13 renk indikatörüne (dimetil sarısı, malakit yeşili, metanil sarı, karminik asit, parlak sar1, m-krezol moru, bromkrezol moru, timol mavisi, fenolftalein ve diğerleri) dayalı bir kromojenik dizi kullanarak, MAP ile paketlenmiş haşlanmış marine edilmiş hindi eti için akıllı araçlar geliştirilmiştir. Kromojenik dizi, renk değişimlerini çıkarmak ve analiz etmek için dijital kamera ve Photoshop gibi araçlarla kombine edilmiştir. Elde edilen veriler, ürünün "taze", "taze değil" veya "tüketilemez" olarak sınıflandırılmasını sağlamıştır (Salinas vd., 2014). Hidroksipropil selüloz (HPC) içinde kapsüllenmiş tiyazin boyalarının (metilen mavisi, MB) kümelenmesine dayanan bir renk değişimi ile neme duyarlı kolorimetrik indikatör geliştirilmiştir. Başlangıçta mor renkli olan $\mathrm{MB} / \mathrm{HPC}$ film, isıl işlemle aktive edilerek mavi renk almaktadır. Isıl işlem görmüş MB/HPC film (mavi), $21^{\circ} \mathrm{C}$ 'de ortamdaki nem değeri $\% 70^{\prime} \mathrm{i}$ aştığında neme bağlı olarak mor rengine geri dönerek yanıt vermektedir (Mills vd., 2017). Bir diğer çalışmada, soğukta depolanan kalamarın raf ömrünün değerlendirilmesi için hızlı, kullanımı kolay bir optoelektronik sistem geliştirilmiştir. Bu amaçla, farklı boyaların (timol mavisi, bromtimol mavisi, bromkrezol pembesi, dinükleer rodyum kompleksi, bromfenol mavisi) alüminyum oksit ve silika jel ile birleştirilmesiyle hazırlanan alt1 algılama materyali içeren bir kolorimetrik diziden oluşan optoelektronik sensör tasarlanmıştır ve kolorimetrik diziyle kalamar tazeliği arasında uyum bulunmuştur (Zaragozá vd., 2015).

Pek çok ticari akıllı ambalajlama, geliştirilen sensörlerin ve indikatörlerin kullanımına dayanmaktadır. Et endüstrisinde sensörlerin yaygın kullanımına yönelik önemli adımlar atılmıştır. Ticari bir örnek olan UPM Raf Ömrü (UPM, Helsinki, Finlandiya) gösterge etiketi, modifiye atmosfer paketlerinin bütünlügünü izleyebilmektedir. Ambalajın iç kısmına eklenen etiket, şeffaf dış paketten görülebilmektedir ve lamine tabakalar arasinda tutulan oksijenle reaksiyona girebilen bir redoks boya içermektedir. Renksiz etiketin maviye doğru bir renk değişimi, paket içinde oksijen varlığını göstererek ambalajı hasar gören veya sızıntı meydana gelen ürünleri belirlemektedir. Başka bir ticari örnek olan
SensorQ ${ }^{\mathrm{TM}}$ yapışkan sensör etiketi, tüketiciye ürün tazeliğini açık bir şekilde göstermek için, et ve tavuk ambalaj paketlerinin iç ambalajina uygulanmaktadır. Etiketteki "Q" harfi iç kısmı portakal rengi olduğunda ürün taze iken, kahverengiye doğru dönüşerek bozulmaya işaret etmektedir (O'Grady ve Kerry, 2008). Smolander vd. (2002) tarafindan MAP ile paketlenmiş tavuk eti ürünleri için hidrojen sülfüre duyarlı agaroza immobilize edilmiş miyoglobin bazlı sensörler geliştirilmiştir. Ambalaj materyaline floresan veya fosforan boyalar yerleştirilmesiyle floresans bazlı sensörler de geliştirilmektedir. $\mathrm{Bu}$ sensörler ortamda bulunan gazın difüze olarak floresan boyaya ulaşması sonucu ambalajın ışıldamasını sağlamaktadır (Karagöz ve Demirdöven, 2017). Bunlara ek olarak, Toxin GuardTM, Toxin Alert (Ontario, Kanada) ve Food Sentinel Systems (SIRA Technologies, Pasadena, CA) tarafindan antibody-antijen reaksiyonlarına dayanan görsel bir sensör geliştirilmiştir. Sensör, polimer ambalaj filmlerine entegre olarak patojenik bakterilerin varlığını göstermektedir (Mohebi ve Marquez, 2015).

\section{SONUÇ}

Gida ambalajlama, nakliye, depolama ve tüketime kadar gıdaların kalitesini korumak için uygulanan ana işlemlerden biridir. Akıllı ambalajlama, gida ambalaj1 alanındaki yeni teknolojilerden biridir. Hızla gelişmekte olan bu teknoloji ticari olarak yaygın olmamasına rağmen, gıda ürünlerinin güvenliğinin ve kalitesinin izlenebilirliği için büyük bir potansiyele sahiptir. Ak1ll 1 ambalaj etiketlerindeki görsel değişim, tüketicinin kendi isteklerine dayanarak ürünün kişisel bir değerlendirmesini yapmasına ve ürünü en iyi şekilde tüketmesine olanak sağlamaktadır. Akıllı ambalajlama teknolojisinin gida endüstrisi tarafından benimsenmesi tüketicilere birçok kolaylık sunacak ve kuşkusuz gıda güvenliğinde iyileştirme sağlayacaktır. Özellikle kolay bozulma özelliği taşıyan gidalar, akıllı ambalajlama için en önemli hedef gruptur. Depolama sirasinda gida bozulma mekanizmasına bağlı olarak ortaya çıkan asitler, aminler, karbondioksit ve aldehitler sonucu değişen pH'nın gida ambalajında izlenmesi, gida maddesinin raf ömrünü gösterebilmektedir. Geliştirilen akıllı ambalaj 
materyallerinde, özellikle paket içerisine yerleştirilenler için, gıdaların bileşimi ve duyusal özellikleri üzerine etkisi, insan sağlı̆̆ üzerindeki potansiyel etkileri ve aynı zamanda yasal düzenlemelerdeki yeri gibi faktörler mutlaka dikkate alınmalıdır.

\section{KAYNAKLAR}

Chen, Y., Fu, G., Zilberman, Y., Ruan, W., Ameri, S. K., Zhang, Y. S., Miller, E., Sonkusale, S. R. (2017). Low cost smart phone diagnostics for food using paper-based colorimetric sensor arrays. Food Control, 82: 227-232, doi: https://doi.org/10.1016/j.foodcont.2017.07.003

Choi, I., Lee, J. Y., Lacroix, M., Han, J. (2017). Intelligent $\mathrm{pH}$ indicator film composed of agar/potato starch and anthocyanin extracts from purple sweet potato. Food Chemistry, 218: 122-128, doi: $\quad$ https://doi.org/10.1016/j.foodchem. 2016.09.050.

Costa, C., Antonucci, F., Pallottino, F., Aguzzi, J., Sarriá, D., Menesatti, P. (2013). A review on agrifood supply chain traceability by means of RFID technology. Food and bioprocess technology, 6(2): 353366, doi: 10.1007/s11947-012-0958-7.

Dalmoro, V., dos Santos, J. H. Z., Pires, M., Simanke, A., Baldino, G. B., Oliveira, L. (2017). 4Encapsulation of sensors for intelligent packaging. In: Food Packaging, Grumezescu, A. M. (chief ed.), Academic Press, pp. 111-145, doi: https://doi.org/10.1016/B978-0-12-8043028.00004-2.

de Kruijf, N.N., van Beest, M., Rijk, R., SipilainenMalm, T., Paseiro, L.P., De Meulenaer, B. (2002). Active and intelligent packaging: applications and regulatory aspects. Food Additives and Contaminants, 19 Suppl:144-162.

Dobrucka, R. (2013). The future of active and intelligent packaging industry. Logforum, 9 (2): 103110. http://www.logforum.net/pdf/9_2_4_13. pdf (Erişim tarihi: 15.08.2018).

Fang, Z., Zhao, Y., Warner, R. D., Johnson, S. K. (2017). Active and intelligent packaging in meat industry. Trends in Food Science \& Technology, 61: 60-
71, doi: https://doi.org/10.1016/j.tifs. 2017.01.002.

Fresh-Check $^{\circledR}$ (2018). Self-adhesive Time Temperature Indicator. http://fresh-check.com/ (Accessed: 28.12.2018).

Ghaani, M., Cozzolino, C. A., Castelli, G., Farris, S. (2016). An overview of the intelligent packaging technologies in the food sector. Trends in Food Science \& Technology, 51: 1-11, doi: https://doi.org/10.1016/j.tifs.2016.02.008.

Heising, J. K., Dekker, M., Bartels, P. V., Van Boekel, M. A. J. S. (2014). Monitoring the Quality of Perishable Foods: Opportunities for Intelligent Packaging. Critical Reviews in Food Science and Nutrition, 54(5): 645-654, doi: 10.1080/10408398. 2011.600477.

Huang, X., Xin, J., Zhao, J. (2011). A novel technique for rapid evaluation of fish freshness using colorimetric sensor array. Journal of Food Engineering, 105(4): 632-637, doi: https://doi.org/ 10.1016/j.jfoodeng.2011.03.034.

Karagöz, Ş., Demirdöven, A. (2017). Gida Ambalajlamada Güncel Uygulamalar: Modifiye Atmosfer, Aktif, Ak1llı ve Nanoteknolojik Ambalajlama Uygulamaları. Gaziosmanpaşa Bilimsel Araştırma Dergisi, 6(1), 9-21.

Karel, M., Lund, D. B. (2003). Physical Principles of Food Preservation. 2nd Edition, Marcel Dekker, New York, U.S.A, 603p.

Kerry, J. P., O'Grady, M. N., Hogan, S. A. (2006). Past, current and potential utilisation of active and intelligent packaging systems for meat and muscle-based products: A review. Meat Science, 74(1): 113-130, doi: https://doi.org/10.1016/ j.meatsci.2006.04.024.

Kerry, J. P., (2014). Chapter 23 - New Packaging Technologies, Materials and Formats for FastMoving Consumer Products. In: Innovations in Food Packaging (Second Edition), Han, J. H. (chief ed.), Academic Press, 549-584, doi: https://doi.org/10.1016/B978-0-12-3946010.00023-0.

Kokangül, G., Fenercioğlu, H. (2012). G1da endüstrisinde ak1llı ambalaj kullanımı. Grda Teknolojileri Elektronik Dergisi, 7(2): 31-43. 
Kuswandi, B., Nurfawaidi, A. (2017). On-package dual sensors label based on $\mathrm{pH}$ indicators for realtime monitoring of beef freshness. Food Control, 82: 91-100, doi: https://doi.org/10.1016/ j.foodcont.2017.06.028.

Lee, S. J., Rahman, A. T. M. M. (2014). Chapter 8 - Intelligent Packaging for Food Products. In: Innovations in Food Packeaging (Second Edition), Han, J. H. (chief ed.), Academic Press, 171-209, doi: https://doi.org/10.1016/B978-0-12-3946010.00008-4.

Liu, B., Xu, H., Zhao, H., Liu, W., Zhao, L., Li, Y. (2017). Preparation and characterization of intelligent starch/PVA films for simultaneous colorimetric indication and antimicrobial activity for food packaging applications. Carbohydrate Polymers, $\quad 157$ : 842-849, doi: https://doi.org/10.1016/j.carbpol.2016.10.067.

Luchese, C. L., Sperotto, N., Spada, J. C., Tessaro I. C. (2017). Effect of blueberry agro-industrial waste addition to corn starch-based films for the production of a $\mathrm{pH}$-indicator film. International Journal of Biological Macromolecules, 104: 11-18, doi: https://doi.org/10.1016/j.ijbiomac.2017.05.149.

Ma, Q., Du, L., Wang, L. (2017). Tara gum/polyvinyl alcohol-based colorimetric NH3 indicator films incorporating curcumin for intelligent packaging. Sensors and Actuators B: Chemical, 244: 759-766, doi: https://doi.org/ 10.1016/j.snb.2017.01.035.

Ma, Q., Liang, T., Cao, L., Wang, L. (2018). Intelligent poly (vinyl alcohol)-chitosan nanoparticles-mulberry extracts films capable of monitoring $\mathrm{pH}$ variations. International Journal of Biological Macromolecules, 108: 576-584, doi: https://doi.org/10.1016/j.ijbiomac.2017.12.049.

Majid, I., Nayik, G. A., Dar, S. M., Nanda, V. (2016). Novel food packaging technologies: Innovations and future prospective. Journal of the Saudi Society of Agricultural Sciences, doi: https://doi.org/10.1016/j.jssas.2016.11.003.

Mills, A., Hawthorne, D., Burns, L., Hazafy, D. (2017). Novel temperature-activated humiditysensitive optical sensor. Sensors and Actuators B: Chemical, 240: 1009-1015, doi: https://doi.org/ 10.1016/j.snb.2016.08.182.
Mohebi, E., Marquez, L. (2015). Intelligent packaging in meat industry: An overview of existing solutions. Journal of Food Science and Technology, 52(7): 3947-3964, doi: 10.1007/s13197014-1588-z.

Morsy, M. K., Zór, K., Kostesha, N., Alstrøm, T. S., Heiskanen, A., El-Tanahi, H., Sharoba, A., Papkovsky, D., Larsen, J., Khalaf, H., Jakobsen, M. H., Emnéus, J. (2016). Development and validation of a colorimetric sensor array for fish spoilage monitoring. Food Control, 60: 346-352, doi: $\quad$ https://doi.org/10.1016/j.foodcont. 2015.07.038.

Musso, Y. S., Salgado, P. R., Mauri, A. N. (2016). Gelatin based films capable of modifying its color against environmental $\mathrm{pH}$ changes. Food Hydrocolloids, 61: 523-530, doi: https://doi.org/ 10.1016/j.foodhyd.2016.06.013.

Niponsak, A., Laohakunjit, N., Kerdchoechuen, O., Wongsawadee, P. (2016). Development of smart colourimetric starch-based indicator for liberated volatiles during durian ripeness. Food Research International, 89: 365-372, doi: https://doi.org/10.1016/j.foodres.2016.08.038.

Nopwinyuwong, A., Trevanich, S., Suppakul, P. (2010). Development of a novel colorimetric indicator label for monitoring freshness of intermediate-moisture dessert spoilage. Talanta, 81(3): 1126-1132, doi: https://doi.org/10.1016/ j.talanta.2010.02.008.

O'Grady, M. N., Kerry, J. P. (2008). Smart Packaging Technologies and Their Application in Conventional Meat Packaging Systems. In: Meat Biotechnology, Toldrá, F. (chief ed.), Springer, New York, 425-451, doi: 10.1007/978-0-387-793825_19.

Otles, S., Sahyar, B. Y. (2016). Chapter 13 Intelligent Food Packaging. In: Comprehensive Analytical Chemistry, Scognamiglio, V., Rea, G., Arduini, F., Palleschi, G. (ed.), Elsevier, 377-387, doi: $\quad$ https://doi.org/10.1016/bs.coac. 2016.04.010.

Öksüztepe, G., Beyazgül, P. (2015). Akıllı Ambalajlama Sistemleri ve Gida Güvenliği. Frat Üniversitesi Sağhlk Bilimleri Veteriner Dergisi, 29(1): 67-74. 
Pereira, V. A., de Arruda, I. N. Q., Stefani, R. (2015). Active chitosan/PVA films with anthocyanins from Brassica oleraceae (Red Cabbage) as Time-Temperature Indicators for application in intelligent food packaging. Food Hydrocolloids, 43: 180-188, doi: https://doi.org/ 10.1016/j.foodhyd.2014.05.014.

Realini, C. E., Marcos, B. (2014). Active and intelligent packaging systems for a modern society. Meat Science, 98(3): 404-419, doi: https://doi.org/10.1016/j.meatsci.2014.06.031.

Salinas, Y., Ros-Lis, J. V., Vivancos, J., MartínezMáñez, R., Aucejo, S., Herranz, N., Lorente, I., Garcia, E. (2014). A chromogenic sensor array for boiled marinated turkey freshness monitoring. Sensors and Actuators B: Chemical, 190: 326-333, doi: https://doi.org/10.1016/j.snb.2013.08.075.

Salinas, Y., Ros-Lis, J. V., Vivancos, J., MartínezMáñez, R., Marcos, M. D., Aucejo, S., Herranz, N., Lorente, I., Garcia, E. (2014). A novel colorimetric sensor array for monitoring fresh pork sausages spoilage. Food Control, 35(1): 166176, doi: https://doi.org/10.1016/j.foodcont. 2013.06.043.

Saliu, F., Pergola, R. D. (2018). Carbon dioxide colorimetric indicators for food packaging application: Applicability of anthocyanin and poly-lysine mixtures. Sensors and Actuators B: Chemical, 258: 1117-1124, doi: https://doi.org/ 10.1016/j.snb.2017.12.007.

Shimoni E., Anderson E. M., Labuza T. P. (2001). Reliability of time temperature indicators under temperature abuse. Journal of Food Science, 66: 1337-1340, doi: https://doi.org/10.1111/j.13652621.2001.tb15211.x.

Shin, J., Selke, S. E. M. (2014). 11-Food Packaging. In: Food Processing: Principles and Applications (Second Edition), Clark, S., Jung, S., Lamsal, B. (ed.), John Wiley \& Sons, 249-273.

Shukla, V., Kandeepan, G., Vishnuraj, M. R., Soni, A. (2016). Anthocyanins Based Indicator Sensor for Intelligent Packaging Application. Agricultural Research, 5(2): 205-209, doi: 10.1007/s40003-016-0211-0.
Singh, R. P., Heldman, D. R. (2014). Chapter 15 Packaging Concepts. In: Introduction to Food Engineering (Fifth Edition), San Diego: Academic Press, 767-791.

Smolander, M., Hurme, E., Latva-Kala, K., Luoma, T., Alakomi, H. L., Ahvenainen, R. (2002). Myoglobin-based indicators for the evaluation of freshness of unmarinated broiler cuts. Innovative Food Science and Emerging Technologies, 3(3): 279-288, doi: https://doi.org/10.1016/ S1466-8564(02)00043-7.

Tang, Z., Yang, J., Yu, J., Cui, B. (2010). A Colorimetric Sensor for Qualitative Discrimination and Quantitative Detection of Volatile Amines. Sensors, 10(7): 6463, doi: https://doi.org/10.3390/s100706463.

Smolander, M. (2008). Freshness indicators and food packaging. In: Smart Packaging Technologies for Fast Moving Consumer Goods, Kerry, J., Butler, P. (ed.), John Wiley \& Sons, England, 111-127.

Taoukis, P., Tsironi, T. (2016). 5 - Smart Packaging for Monitoring and Managing Food and Beverage Shelf Life. In: The Stability and Shelf Life of Food (Second Edition), Subramaniam, P., Wareing, P., Woodhead Publishing, 141-168.

Üçüncü, M. (2011). Gıda Ambalajlama Teknolojisi. Ambalaj Sanayicileri Derneği İktisadi İşletmesi, İstanbul, Türkiye, $896 \mathrm{~s}$.

Vanderroost, M., Ragaert, P., Devlieghere, F., Meulenaer, B. D. (2014). Intelligent food packaging: The next generation. Trends in Food Science \& Technology, 39(1): 47-62, doi: https://doi.org/10.1016/j.tifs.2014.06.009.

Wei, Y., Cheng, C., Ho, Y., Tsai, M., Mi, F. (2017). Active gellan gum/purple sweet potato composite films capable of monitoring $\mathrm{pH}$ variations. Food Hydrocolloids, 69: 491-502, doi: https://doi.org/10.1016/j.foodhyd.2017.03.010.

Xiao-wie, H., Xiao-bo, Z., Ji-yong, S., Yanin, G., Jie-wen, Z., Jianchun, Z., Limin, H. (2014). Determination of pork spoilage by colorimetric gas sensor array based on natural pigments. Food Chemistry, 145: 549-554, doi: https://doi.org/ 10.1016/j.foodchem.2013.08.101. 
Yam, K. L., Paul, T., Miltz, J. (2005). Intelligent Packaging:Concepts and Applications. Journal of Food Science, 70(1): 1-9, doi: https://doi.org/ 10.1111/j.1365-2621.2005.tb09052.x.

Yoshida, C. M. P., Maciel, V. B. V., Mendonça, M. E. D., Franco, T. T. (2014). Chitosan biobased and intelligent films: Monitoring $\mathrm{pH}$ variations. LWT - Food Science and Technology, 55(1): 83-89, doi: https://doi.org/10.1016/j.lwt.2013.09.015.

Yüksel, M. E., Zaim, A. H. (2009). Yeni nesil teknoloji olarak RFID, RFID sistem yapiları ve bir RFID sistem tasarımı yaklaşımı. 5. Uluslararası İleri Teknolojiler Sempozyumu (IATS’09), 13-15 Mayıs 2009, Karabük, Türkiye.

Zaragozá, P., Fuentes, A., Ruiz-Rico, M., Vivancos, J., Fernández-Segovia, I., Ros-Lis, J.V., Barat, J. M., Martínez-Máñez, R. (2015). Development of a colorimetric sensor array for squid spoilage assessment. Food Chemistry, 175: 315-321, doi: https://doi.org/10.1016/ j.foodchem.2014.11.156.
Zhai, X., Shi, J., Zou, X., Wang, S., Jiang, C., Zhang, J., Huang, X., Zhang, W., Holmes, M. (2017). Novel colorimetric films based on starch/polyvinyl alcohol incorporated with roselle anthocyanins for fish freshness monitoring. Food Hydrocolloids, 69: 308-317, doi: https://doi.org/10.1016/j.foodhyd.2017.02.014.

Zhang, J., Zou, X., Zhai, X., Huang, X., Jiang, C., Holmes M. (2018). Preparation of an Intelligent pH Film Based on Biodegradable Polymers and Roselle Anthocyanins for Monitoring Pork Freshness. Food Chemistry, 272: 306-312, doi: https://doi.org/10.1016/j.foodchem.2018.08.04 1.

Zhang, X., Lu, S., Chen, X. (2014). A visual pH sensing film using natural dyes from Bauhinia blakeana Dunn. Sensors and Actuators B: Chemical, 198: 268-273, doi: https://doi.org/10.1016/ j.snb.2014.02.094. 